\begin{tabular}{|lll|}
\hline Diterima & $:$ & 26 Desember 2020 \\
Direvisi & $:$ & 15 Februari 2021 \\
Disetujui & $:$ & 30 Juni 2021 \\
Diterbitkan & $:$ & 30 Juni 2021 \\
\hline
\end{tabular}

\title{
EFEKTIVITAS PENGGUNAAN MEDIA BALOK CUISENAIRE TERHADAP KEMAMPUAN MENGENAL KONSEP LAMBANG BILANGAN PADA ANAK USIA 4-5 TAHUN
}

\author{
Ditha Sandyprihati ${ }^{1}$, Upik Elok Endang Rasmani ${ }^{2}$, Ruli Hafidah ${ }^{3}$ \\ email: dithasandy123@gmail.com¹, upikelok@staff.uns.ac.id², \\ rulihafidah@staff.uns.ac.id ${ }^{3}$ \\ Program Studi Pendidikan Guru Pendidikan Anak Usia Dini, \\ Universitas Sebelas Maret Surakarta
}

Jalan Ir. Sutami No.36, Kentingan, Kec. Jebres, Kota Surakarta, Jawa Tengah 57126, Indonesia

\begin{abstract}
Abstrak: Pengenalan konsep lambang bilangan pada anak usia 4-5 tahun atau anak TK kelompok A harus diiringi dengan benda konkrit atau nyata agar potensi yang mereka miliki dapat berkembang secara optimal. Tujuan penelitian ini adalah untuk mengetahui efektivitas penerapan Balok Cuisenaire terhadap kemampuan mengenal konsep lambang bilangan terhadap anak usia 4-5 tahun dalam kegiatan pembelajaran. Penelitian ini merupakan penelitian kuasi eksperimen yang berbentuk nonequivalent control grup design. Penelitian dilaksanakan selama satu bulan dengan 6 kali pertemuan pada setiap kelompok. Teknik pengambilan sampel yang digunakan adalah sampel bertujuan. Penelitian dilaksanakan di sebuah taman kanak-kanak di Kota Surakarta. Partisipan penelitian ini adalah kelompok eksperimen berjumlah 21 anak dan kelompok kontrol berjumlah 21 anak. Analisis data terdiri dari uji prasyarat dan uji hipotesis. Hasil uji prasyarat menggunakan Shapiro Wilk dan Levene Test for Equality of Variance yang menunjukkan bahwa data bersifat normal dan homogen. Sedangkan pada uji hipotesis menggunakan paired sample t-test untuk uji pre-post dalam kelompok yang sama dan independent sample $t$-test untuk uji beda antar kelompok dengan membandingkan skor kelompok kontrol dengan eksperimen pada signifikasi $p<0,05$. Hasil penelitian menunjukkan rata-rata pretest kelompok eksperimen dan kontrol adalah 16,05 dan 15,90 dengan nilai signifikansi 0,758 . Sedangkan rata-rata posttest kelompok eksperimen dan kontrol adalah 22,29 dan 16,33 dengan nilai signifikansi 0,000 . Nilai signifikansi posttest kelompok eksperimen dan kontrol $0,000 \leq 0,05$ sehingga dapat disimpulkan bahwa terdapat efektivitas penggunaan media balok Cuisenaire terhadap perkembangan mengenal konsep lambang bilangan pada anak usia 4-5 tahun.
\end{abstract}

Kata-kata Kunci: anak usia 4-5 tahun, balok cuisenaire, lambang bilangan, perkembangan kognitif

\section{THE EFFECTIVENESS OF CUISENAIRE BLOCK MEDIA USAGE ON THE CONCEPT OF NUMBER SYMBOLS RECOGNITION ABILITY IN CHILDREN AGED 4-5}

\begin{abstract}
The introduction of the concept of number symbols in children aged 4-5 years or kindergarten children group A must be accompanied by concrete or tangible objects so that their potential can develop optimally. The purpose of this study is to find out the effectiveness of the application of Cuisenaire Blocks to the ability to recognize the concept of number symbols to children aged 4-5 years in learning activities. This research is a quasi-experimental study in the form of a nonequivalent control group design. In this research, each group conducts six meetings each month. The sampling technique used is purposive
\end{abstract}


sampling. Participants in this study were an experimental and control group, both consists of 21 children. Data analysis consists of prerequisite and hypothesis tests. The prerequisite test results using Shapiro Wilk and the Levene Test for Equality of Variance showed that the data was usual and homogeneous. While in the hypothesis test using paired sample t-test for pre-post test in the same group and independent sample t-test for different tests between groups by comparing the score of the control and experiment groups on signification $p<0.05$. The results showed that the average pretest of the experiment and control group was 16.05 and 15.90, with a significance score of 0.758 . Meanwhile, the average posttest of the experiment and control group was 22.29 and 16.33, with a significance score of 0.000 . Based on the experiment and control group significance score of $0.000 \leq 0.05$, this research concluded that Cuisenaire block media usage develops the concept of number symbols recognition ability in children aged 4-5.

Keywords: children aged 4-5, cuisenaire rods, cognitive development, number symbols

\section{PENDAHULUAN}

Usia dini merupakan masa peka yang sangat penting bagi anak untuk mendapatkan pendidikan yang sesuai dengan umurnya. Pengalaman yang didapatkan dari lingkungannya, termasuk stimulasi yang diberikan akan berpengaruh besar bagi kehidupan anak dimasa mendatang. Oleh karena itu diperlukan upaya yang tepat agar tumbuh kembang anak dapat berlangsung secara optimal dengan memberikan kegiatan pendidikan dan pembelajaran yang sesuai dengan usia, kebutuhan, dan minat anak.

Kemampuan kognitif yang perlu dikembangkan salah satunya adalah kemampuan dalam mengenal konsep lambang bilangan. Salah satu aspek dalam pengembangan kognitif ini adalah pengembangan kemampuan mengenal angka 1-10. Kemampuan tersebut menjadi dasar bagaimana anak mampu menyelesaikan masalah sehari-hari terurtama hal yang terkait dengan angka. Ketika anak mampu menguasai kemampuan mengenal angka dengan baik, maka akan menjadi dasar bagi pengembangan kemampuan mengenal angka maupun kesiapan untuk mengikuti pendidikan dasar.

Permendikbud Nomor 137 Tahun 2014 tentang Standar Tingkat Pencapaian Perkembangan Anak (STPPA) disebutkan bahwa anak usia 4-5 tahun hendaknya sudah mulai mengembangkan pemahaman konsep lambang bilangan. Kemampuan mengenal konsep lambang bilangan pada anak usia 4-5 tahun atau anak TK kelompok $A$ adalah anak sudah mampu mengetahui konsep banyak $d$ an sedikit, membilang banyak benda satu sampai sepuluh, mengenal konsep bilangan, serta mengenal lambang bilangan dari angka satu sampai sepuluh.

Sujiono \& Nurani (2011), menjelaskan beberapa indikator tentang kemampuan lambang bilangan anak usia 4-5 tahun adalah: 1) Pengenalan kualitas (jumlah) yaitu anak-anak menghitung semumlah benda yang telah ditentukan secara bertahap dari 1-5 lalu 6-10; 2) Menghafal urutan nama bilangan yaitu menyebutkan nama bilangan dengan urutan yang benar; 3) Menghitung secara rasional; 4) Menghitung maju; 5) Menghitung mundur; dan 6) Menghitung melompat.

Hasil observasi yang dilakukan pada selama 5 hari sebuah TK di Kota Surakarta memperlihatkan bahwa kemampuan anak usia 4-5 tahun dalam mengenal konsep lambang bilangan masih kurang. Anak hanya mengerti konsep lambang bilangan pada sebatas hafalan lisan saja, sehingga anak masih seringkali terbalik-balik dalam menyebutkan nama lambang bilangan. Proses anak saat membilang juga belum tepat yaitu ketidaksesuaian antara pengucapan dengan jumlah benda yang dihitung. Anak juga belum mampu membedakan dan membuat dua kelompok benda yang memiliki jumlah sama, tidak sama, lebih banyak serta lebih sedikit. Indikator yang dipakai dalam observasi adalah : (a) anak mampu membaca bilangan 1 sampai 10; (b) anak mampu menuliskan lambang bilangan 1 sampai 10; (c) anak mampu menyatakan jumlah bilangan dari sekumpulan benda (1-10); (d) anak mampu menghubungkan lambang bilangan dengan jumlah benda; (e) anak mampu membandingkan lebih banyak atau sedikit jumlah suatu benda (1-10); (f) anak mampu menentukan urutan kumpulan dari yang terbesar ke terkecil maupun sebaliknya (1-10); (g) anak mampu menentukan bilangan yang hilang dalam urutan 1-10.

Wawancara yang peneliti lakukan dengan guru kelas sebelum melakukan treatment yakni pada tanggal 22 Juli 2019 mendapatkan hasil bahwa: (a) kemampuan mengenal konsep lambang bilangan pada anak saat ini baru berkembang sekitar 30\%; (b) terdapat hambatan dalam penyampaian materi karena kebosanan yang dialami anak karena menggunakan 
metode atau pun media yang monoton tanpa ada interaksi dua arah.

Hal ini jika tidak segera ditangani maka akan menjadi masalah pada anak di kemudian hari. Pemahaman konsep lambang bilangan pada anak suatu hal yang penting dan mendasar bagi anak usia dini untuk mempelajari matematika permulaan. Konsep lambang bilangan merupakan konsep matematika yang sangat penting untuk dikuasai oleh anak, karena akan menjadi dasar bagi penguasaan konsep- konsep matematika selanjutnya. Dengan memahami konsep bilangan, diharapkan anak juga akan dapat memahami konsep matematika yang lain.

Dalam pembelajaran berhitung guru perlu memilih media yang menarik dan menyenangkan bagi anak agar pengenalan berhitung dapat diserap anak secara optimal. Pengembangan berhitung tersebut harus sesuai dengan tahap perkembangan anak supaya anak bisa mengekspresikan diri secara bebas. Peningkatan kemampuan mengenal lambang bilangan 1-10 pada anak usia 4-5 tahun dapat dikembangkan melalui adanya media pembelajaran, yaitu salah satunya dengan media balok cuisenaire. Media balok cuisenaire adalah alat peraga yang digunakan untuk mempermudah siswa untuk memahami matematika dengan menggunakan balok yang berwarna- warni berukuran kecil dengan angka 1-10 (Eliyawati 2005). Penggunaan metode yang tepat akan membuat anak merasa nyaman dan senang saat melakukan proses pembelajaran, mereka tidak akan merasa tertekan dan tanpa sadar mereka telah belajar dan mendapatkan pengalaman serta informasi.

Berdasarkan uraian di atas, maka penelitian ini mengkaji penerapan media balok cuisenaire terhadap kemampuan mengenal konsep lambang bilangan pada anak usia 4-5 Tahun.

\section{LAMBANG BILANGAN}

Gagne (dalam Jamaris, 2006) mengatakan bahwa perkembangan kognitif adalah proses yang terjadi secara internal di dalam pusat susunan syaraf pada waktu manusia sedang berpikir. Menurut Sujiono \& Nurani (2011) perkembangan kognitif ditandai oleh suatu kemampuan untuk merencanakan, menjalankan suatu strategi untuk mengingat dan untuk mencari solusi terhadap suatu permasalahan.

Sriningsih (2009) mendefinisikan lambang bilangan adalah ilmu tentang struktur yang saling berhubungan, yang maknanya berhitung adalah ilmu yang berhubungan dengan penelaah bentuk, struktur-struktur abstrak dan hubungan diantara hal-hal tersebut dalam berhitung terorganisasikan dengan baik, sistematis dan logis. Bilangan mewakili banyaknya suatu benda. Lambang bilangan tersebut juga angka. Dengan cara menulis dan membaca lambang bilangan dengan gambar dikatakan bahwa suatu idea yang hanya dapat dihayati atau dipikirkan saja. Bruner menyatakan bahwa perkembangan pemahamann konsep lambang bilangan melalui 3 tahapan, yaitu: 1) tahap enaktif, 2) tahap ikonok, dan 3) tahap simbolik (Sriningsih, 2008).

\section{PERKEMBANGAN ANAK USIA 4-5 TAHUN}

Fase perkembangan kognitif menurut Piaget pada anak usia 4-5 tahun berada pada fase praoperasional. Wonlfiger (dalam Susanto, 2011) mengemukakan bahwa cara berpikir anak berpijak pada pengalaman benda-benda konkret, bukan dari pengetahuan atau konsep-konsep yang abstrak. Anak berpikir dengan cara berinterksi langsung dengan benda-benda konkret atau nyata sehingga anak akan mendapatkan informasi dan pengetahuan.

Berbagai pendekatan yang dapat digunakan untuk mengenalkan kompetensi matematika awal pada anak adalah dengan melakukan kegiatan yang menantang, tepat, dan adaptif karena mengingat bahwa kemampuan mengenal konsep lambang bilangan sangat penting untuk anak pada masa sekarang dan bahkan untuk pendidikan selanjutnya (Vogt et al., 2018).

\section{MEDIA BALOK CUISENAIRE}

George Cuisenaire (dalam Eliyawati, 2005) mengemukakan bahwa balok cuisenaire merupakan balok yang terdiri atas balok-balok yang dengan ukuran sebagai berikut: $1 \times 1 \times 1 \mathrm{~cm}$ berwarna kayu asli; $2 \times 1$ $x 1 \mathrm{~cm}$ berwarna merah; $3 \times 1 \times 1 \mathrm{~cm}$ berwarna hujau muda; $4 \times 1 \times 1 \mathrm{~cm}$ berwarna merah muda; $5 \times 1 \times 1$ $\mathrm{cm}$ berwarna kuning; $6 \times 1 \times 1 \mathrm{~cm}$ berwarna hijau tua; $7 \times 1 \times 1 \mathrm{~cm}$ berwarna hitam; $8 \times 1 \times 1 \mathrm{~cm}$ berwarna coklat; $9 \times 1 \times 1 \mathrm{~cm}$ berwarna biru tua; $10 \times 1 \times 1 \mathrm{~cm}$ berwarna jingga.

Balok cuisenaire diciptakan untuk mengembangkan kemampuan berhitung pada anak, pengenalan bilangan, dan untuk peningkatan keterampilan anak dalam bernalar. Balok cuisenaire ini merupakan salah satu Alat Permainan Edukatif (APE) untuk anak usia dini. Balok cuisenaire terbuat dari kayu dan dicat dengan warna yang bermacammacam, balok tersebut merupakan media yang tahan lama (Eliyawati, 2005). Sudono (2006) menjelaskan bahwa balok cuisenaire bukan hanya sekedar mengembangkan konsep matematika, tetapi untuk pengembangan bahasa dan untuk peningkatan keterampilan anak. 
Setiap media tentunya memiliki kelebihan sekaligus kekurangan yang dimiliki, walaupun kekurangan yang ada tidak sebanding dengan banyaknya manfaat yang diberikan. Kekurangan dari balok ini adalah masalah keamanan dan keselamatan bagi anak-anak saat memainkannya yang bisa saja berebut dan melemparkannya kepada teman saat sedang berebut balok. Sehingga walaupun anak terlihat senang saat memainkannya, tetapi peran guru haruslah tetap ada dalam mengawasi dan menjaga saat anak-anak sedang bermain agar tidak terjadi hal yang tidak diinginkan (Kustandi 2016).

\section{METODE PENELITIAN}

Penelitian ini menggunakan desain penelitian quasi experimental dengan tipe non equivalent control group design. Populasi yang digunakan dalam penelitian ini adalah seluruh siswa TK yang berada di Gugus V Anggrek Jebres di Kota Surakarta. Kemudian terpilih dua TK secara purpossive sampling yakni di TK 1 sebagai kelompok eksperimen dan TK 2 sebagai kelompok kontrol karena terdapat masalah pada kemampuan kognitif memahami konsep lambang bilangan. Penentuan kelompok dengan cara pengundian sebanyak 1 kali. Sampel untuk kelompok eksperimen sejumlah 21 anak sedangkan untuk kelompok kontrol berjumlah 21 anak. Kedua kelompok siswa tersebut adalah anak usia 4-5 tahun.

Penelitian ini menggunakan tes untuk mengetahui tingkat pemahaman mengenal konsep lambang bilangan. Tes tersebut berbentuk tes lisan dan tes tertulis. Tes lisan digunakan berbentuk soal lisan oleh guru, sedangkan tes tertulis berbentuk Lembar Kerja Anak (LKA).

Kelompok eksperimen pembelajaran dengan menggunakan balok cuiseniare sedangkan kelompok kontrol menggunakan LKA. Kegiatan penelitian dilaksanakan pada bulan Juli 2019.

Uji validitas instrumen menggunakan validitas isi (content validity) dengan mengacu pada instrumen perkembangan kemampuan konsep lambang bilangan anak yang dikonsultasikan kepada ahli (expert judgment). Data hasil uji coba instrumen diuji dengan menggunakan uji daya beda melalui pengorelasian antara skor item dalam satu faktor. Dasar pengambilan keputusan yakni apabila korelasi $\geq 0,3$ pada setiap faktor (Azwar, 2013) serta memiliki nilai positif maka item dapat dinyatakan valid.

Uji reliabilitas dalam peneltian ini menggunakan Alpha Cronbach's. Uji normalitas data menggunakan Shapiro Wilk dan uji homogenitas menggunakan Levene Test for Equality of Variance. Uji hipotesis (efektivitas media balok Cuisenaire terhadap kemampuan mengenal konsep lambang bilangan pada anak usia 4-5 tahun) menggunakan paired sample t-test untuk uji pre-post dalam kelompok yang sama dan independent sample t-test untuk uji beda antar kelompok dengan membandingkan skor kelompok kontrol dengan eksperimen pada signifikasi $\boldsymbol{p}<0,05$.

\section{HASIL DAN PEMBAHASAN}

Uji normalitas dan homogenitas dilakukan untuk mengetahui apakah data yang diperoleh berdistribusi normal dan homogen. Berikut hasil uji normalitas dan homogenitas:

Tabel 1.

Hasil Uji Normalitas Shapiro-Wilk

\begin{tabular}{llcl}
\hline \multicolumn{1}{c}{ Variabel } & N & $\mathbf{p}$ & Kriteria \\
\hline Ek (Pretest) & 21 & 0,091 & \\
Ek (Posttest) & 21 & 0,063 & \\
Ko (Pretest) & 21 & 0,088 & $p>0,05$ \\
Ko (Posttest) & 21 & 0,127 & \\
\hline
\end{tabular}

Masing-masing variabel tersebut memiliki nilai probabilitas $(p)>0,05$ sehingga dapat disimpulkan bahwa data dalam penelitian ini berdistribusi normal.
Tabel 2.

Hasil Uji Homogenitas

\begin{tabular}{cccc}
\hline & Kelompok & $\mathbf{p}$ & Kriteria \\
\hline \multirow{2}{*}{ Ek } & Pretest & 0,193 & \\
& Posttest & & $p>0,05$ \\
Ko & $\begin{array}{l}\text { Pretest } \\
\text { Posttest }\end{array}$ & 0,984 & \\
\hline
\end{tabular}

Hasil pengujian homogenitas dengan menggunakan metode Levene Test Equality of Variance menunjukkan pada data pretest dan posttest dari kelompok eksperimen nilai probabilitas $(p)$ sebesar 0,193 , dan data pretest dan posttest dari kelompok kontrol nilai probabilitas $(p)$ sebesar 0,984 . Nilai probabilitas dari masing-masing kelompok tersebut memiliki nilai probabilitas $(p)>$ 0,05 sehingga dapat disimpulkan bahwa data dalam 
penelitian ini memiliki variasi yang sama (bersifat homogen).

Kemampuan mengenal konsep lambang bilangan sebelum dilakukan perlakuan (pretest) pada kelompok eksperimen dan kontrol.

Tabel 3.

Deskripsi Pretest (Kemampuan Awal)

\begin{tabular}{lcccccc}
\hline & N & Min & Max & R & Mean & $\begin{array}{c}\text { Std. } \\
\text { Dev }\end{array}$ \\
\hline Ekperimen & 21 & 14,00 & 19,00 & 5 & 16,05 & 1,564 \\
Kontrol & 21 & 14,00 & 19,00 & 5 & 15,90 & 1,411 \\
\hline
\end{tabular}

Tabel di atas menunjukkan skor minimum kemampuan awal pretest pada kelompok eksperimen sebesar 14,00, skor maksimum 19,00, nilai range 5, skor rata- rata atau mean sebesar 16,05 dan standar deviasi sebesar 1,564 . Sedangkan pada kelompok kontrol skor minimum 14,00, maksimum 19,00, range 5, skor rata- rata atau mean sebanyak 15,90 dan standar deviasi sebesar 1,411. Data pretest pada kelompok eksperimen dan kelompok kontrol menunjukkan bahwa kemampuan mengenal lambang bilangan pada anak usia 4-5 tahun terlihat cenderung sama, hal ini ditunjukkan dengan hasil dari mean atau skor rata-rata yang hampir sama dan terpaut selisih 0,15 dengan skor lebih tinggi pada kelompok eksperimen.

Kemampuan mengenal konsep lambang bilangan setelah dilakukan perlakuan (posttest) pada kelompok eksperimen dan kontrol.

Tabel 4.

Deskripsi Posttest (Setelah Treatment)

\begin{tabular}{lcccccc}
\hline & N & Min & Max & R & Mean & $\begin{array}{r}\text { Std. } \\
\text { Dev }\end{array}$ \\
\hline Ekperimen & 21 & 20,00 & 25,00 & 5 & 22,29 & 1,146 \\
Kontrol & 21 & 14,00 & 19,00 & 5 & 16,33 & 1,354 \\
\hline
\end{tabular}

Tabel 4 di atas menunjukkan skor minimum posttest pada kelompok eksperimen sebesar 20,00, maksimum sebesar 25,00, range sebesar 5, skor ratarata atau mean sebesar 22,29 dan standar deviasi sebesar 1,146 . Sedangkan pada kelompok kontrol skor minimum 14,00, skor maksimum 19,00, range sebesar 5 , skor rata-rata atau mean sebesar 16,33 dan standar deviasi 1,354. Data posttest pada kelompok eksperimen menunjukkan bahwa kemampuan mengenal lambang bilangan pada anak usia 4-5 tahun terlihat meningkat lebih tinggi dibanding kelompok kontrol, yaitu dengan selisih sebanyak 5,96.

Kesimpulannya bahwa kemampuan dalam mengenal konsep lambang bilangan pada anak usia 4-5 tahun menggunakan balok cuisenaire lebih unggul dibandingkan dengan LKA.
Tabel 5.

Hasil Uji Beda Kemampuan Awal (Pretest)

\begin{tabular}{clcc}
\hline Treatment & \multicolumn{1}{c}{$\mathbf{K}$} & Mean & $\mathbf{p}$ \\
\hline \multirow{2}{*}{ Pretest } & Ekperimen & 16,05 & \\
& Kontrol & 15,90 & 0,758 \\
\hline
\end{tabular}

Tabel 5 memperlihatkan bahwa skor rata-rata pada kelas eksperimen sebesar 16,05 , dan skor ratarata kelompok kontrol sebesar 15,90 . Hasil perhitungan dari analisis data uji independent samples t-test nilai probabilitas $(0,758)>0,05$, berarti tidak terdapat perbedaan kemampuan mengenal konsep lambang bilangan sebelum dilakukan perlakuan (treatment) pada kelompok eksperimen dan kontrol. Hasil tersebut dapat disimpulkan bahwa kemampuan anak usia 4-5 tahun dalam mengenal konsep lambang bilangan dari kedua kelompok tersebut sebelum adanya perlakuan (treatment) adalah sama.

Tabel 6.

Hasil Uji Beda Kelompok Eksperimen

\begin{tabular}{lllc}
\hline Kelompok & Treatment & Mean & p \\
\hline \multirow{2}{*}{ Ekperimen } & Pretest & 16,05 & \multirow{2}{*}{0,000} \\
& Posttest & 22,29 & \\
\hline
\end{tabular}

Tabel 6 memperlihatkan bahwa skor rata-rata pretest sebesar 16,05 meningkat setelah adanya perlakuan (posttest) menjadi 22,29, dengan demikian pembelajaran menggunakan balok cuiseniare dapat meningkatkan kemampuan mengenal konsep dan lambang bilangan. Hasil perhitungan dari analisis data uji paired samples $t$-test nilai probabilitas $(0,000)<$ 0,05 , berarti terdapat perbedaan tingkat kemampuan mengenal konsep lambang bilangan pada anak usia 4-5 tahun sebelum dan setelah dilakukan perlakuan (treatment) balok cuisenaire.

Tabel 7.

Hasil Uji Beda Kelompok Kontrol

\begin{tabular}{clcc}
\hline Kelompok & Treatment & Mean & p \\
\hline \multirow{2}{*}{ Kontrol } & Pretest & 15,90 & \multirow{2}{*}{0,353} \\
& Posttest & 16,33 & \\
\hline
\end{tabular}

Tabel 7 memperlihatkan bahwa pembelajaran dengan menggunakan LKA tidak dapat meningkatkan kemampuan mengenal konsep dan lambang bilangan dapat dilihat dari skor rata-rata perlakuan (mean) posttest sebesar 16,33 , sedangkan skor rata-rata pretest sebesar 15,90 dan pada hasil perhitungan dari analisis data uji paired samples t-test nilai probabilitas $(0,353)>0,05$, berarti tidak terdapat perbedaan tingkat kemampuan mengenal konsep lambang bilangan pada anak usia 4-5 tahun sebelum dan setelah dilakukan perlakuan (treatmen) LKA. 
Tabel 8

Hasil Uji Beda Eksperimen dan Kontrol (Posttest)

\begin{tabular}{clcc}
\hline Treatment & \multicolumn{1}{c}{$\mathbf{K}$} & Mean & $\mathbf{p}$ \\
\hline \multirow{2}{*}{ Posttest } & Ekperimen & 22,29 & \multirow{2}{*}{0,000} \\
& Kontrol & 16,33 & \\
\hline
\end{tabular}

Tabel 8 memperlihatkan bahwa skor rata-rata perlakuan (mean) posttest pada kelompok eksperimen sebesar 22,29, sedangkan nilai rata-rata posttest pada kelompok kontrol sebesar 16,33, maka pembelajaran dengan menggunakan balok cuiseniare lebih unggul dalam meningkatkan kemampuan mengenal konsep dan lambang bilangan dan hasil analisis data uji independent samples $t$-test nilai probabilitas $(0,000)<0,05$, berarti terdapat perbedaan tingkat kemampuan mengenal konsep lambang bilangan setelah dilakukan perlakuan (treatment) pada kelompok eksperimen dengan kelompok kontrol. Hasil tersebut dapat disimpulkan bahwa adanya efektivitas Balok Cuisenaire terhadap kemampuan mengenal konsep lambang bilangan pada anak usia 4-5 tahun.

Hasil dari pembelajaran konsep lambang bilangan menggunakan balok cuisenaire pada penelitian ini adalah pembelajaran mengenai konsep lambang bilangan yang diberikan kepada anak menggunakan balok cuisenaire yang bertujuan untuk mengembangkan kompetensi mengenal konsep lambang bilangan baik dalam membilang, menghubungkan, dan mengurutkan bilangan. Hal ini sejalan dengan pendapat Edden \& Potter (2013) berpendapat bahwa kemampuan atau kepekaan terhadap konsep lambang bilangan merupakan pondasi awal untuk kecerdasan matematik. Kemampuan mengenal lambang bilangan ini nantinya merupakan kemampuan dasar bagi penguasaan operasi-operasi matematika di jenjang pendidikan formal selanjutnya.

Skor rata-rata pretest pada kelompok eksperimen sebesar 16,05 meningkat setelah adanya perlakuan (posttest) menjadi 22,29. Peningkatan rata-rata yang terjadi pada kelompok eksperimen tersebut dikarenakan kelompok eksperimen mendapat perlakuan atau treatment dengan menggunakan balok cuisenaire. Dengan diberikannya media pembelajaran balok cuisenaire dapat menarik perhatian dan antusias anak dalam mengikuti proses pembelajaran konsep lambang bilangan. Hal ini terlihat saat anak mengikuti kegiatan pembelajaran, anak terlihat lebih senang, antusias dan lebih fokus.

\section{PENUTUP}

Kesimpulan dalam penelitian ini adalah, kemampuan dalam mengenal konsep lambang bilangan pada anak usia 4-5 tahun menggunakan balok cuisenaire lebih unggul dibandingkan dengan LKA. Dengan demikian adanya efektivitas balok cuisenaire terhadap kemampuan mengenal konsep lambang bilangan pada anak usia 4-5 tahun.

Penggunan balok cuisenaire berpengaruh positif terhadap kemampuan konsep lambang bilangan, sehingga anak-anak mampu membilang, menghubungkan, dan mengurutkan bilangan dengan baik. Melalui balok cuisenaire yang diterapkan dalam pembelajaran di kelas, maka akan menciptakan suasana belajar yang menyenangkan, aktif, dan bermakna bagi anak. Hal ini terlihat dari antusias anak saat bermain dengan Balok Cuisenaire, sehingga akan berpengaruh pada aktivitas selama mengikuti kegiatan pembelajaran.

\section{DAFTAR PUSTAKA}

Azwar, S. (2013). Metode Penelitian. Yogyakarta Pustaka Pelajar.

Eden, K. M. \& Potter, E. F. (2013) An exploratory look at the relationships among math skills, motivational factors and activity choice, Early Childhood Education Journal, 41, 235-243. DOI:10.1007/ s10643-012-0540-y

Eliyawati, C. (2005). Pemilihan dan Pengembangan Sumber Berlajar untuk Usia Dini. Jakarta: Dikti Depdiknas.

Jamaris, M. (2006). Perkembangan dan Pengembangan Anak Usia Taman Kanak-Kanak. Jakarta: Grasindo.

Kustandi, C. \& Sutjipto, B. (2016). Media Pembelajaran. Ghalia Indonesia.

Permendikbud No. 137 Tahun 2014 tentang Standar Pendidikan Anak Usia Dini. Kementrian Pendidikan Nasional Direktorat Jenderal
Manajemen Pendidikan Dasar dan Menengah Direktorat Pembinaan TK dan SD. Jakarta.

Sriningsih, N. (2009). Pembelajaran Matematika Terpadu untuk Anak usia Dini. Bandung: Pustaka Sebelas Sudono, A. (2006). Sumber Belajar Dan Alat Permainan. Jakarta: PT. Grasindo.

Sujiono, \& Nurani, Y. (2011). Konsep Dasar Pendidikan Anak Usia dini. Jakarta: PT Indeks.

Susanto, A. (2011). Perkembangan Anak Usia Dini Pengantar Dalam Berbagai Aspeknya. Jakarta: Kencana Perdana Media Group

Vogt, F., Hauser, B., Stebler, R., Rechsteiner, K., \& Urech, C. (2018). Learning through play- pedagogy and learning outcomes in early childhood mathematics. European Early Childhood Education Research Journal, 26 (4), 589-603. DOI: 10.1080/1350293X.2018.1487160 